\title{
AN ECONOMIC TAKE ON PATENT LICENSING: UNDERSTANDING THE IMPLICATIONS OF THE "FIRST SALE PATENT EXHAUSTION" DOCTRINE
}

\author{
Ann Layne-Farrar, Gerard Llobet and A. Jorge Padilla
}

CEMFI Working Paper No. 1002

February 2010

CEMFI

Casado del Alisal 5; 28014 Madrid

Tel. (34) 914290551 Fax (34) 914291056

Internet: www.cemfi.es

We wish to thank Guillermo Caruana, Richard Epstein, Scott Kieff, and Klaus Schmidt for helpful comments and suggestions and Alina Marinova for research assistance. Financial support from Qualcomm is gratefully acknowledged. The ideas and opinions in this paper are exclusively our own. 
CEMFI Working Paper 1002

January 2010

\title{
AN ECONOMIC TAKE ON PATENT LICENSING: UNDERSTANDING THE IMPLICATIONS OF THE "FIRST SALE PATENT EXHAUSTION" DOCTRINE
}

\begin{abstract}
Under the legal doctrine of first sale, or patent exhaustion, a patent holder's ability to license multiple parties along a production chain is restricted. How and when such restrictions should be applied is a controversial issue, as evidenced by the Supreme Court's granting certiorari in the Quanta case. The issue is important, as it has significant implications for how firms can license in vertically disaggregated industries. We explore this issue from an economic viewpoint and find that under ideal circumstances how royalty rates are split along the production chain has no real consequence for social welfare. Even when we depart from ideal conditions, however, we still find no economic justification for a strict application of patent exhaustion. To the contrary, we show there are often private and social advantages to charging royalties at multiple stages. Our results advocate for a flexible application of the first sale doctrine, where exhaustion holds as a default rule but can be easily overwritten in patent contracts.
\end{abstract}

Anne Layne-Farrar

LECG Consulting alayne-farrar@lecg.com
Gerard Llobet

CEMFI

llobet@cemfi.es
A. Jorge Padilla LECG Consulting jpadilla@lecg.com 


\section{Introduction}

In the summer of 2008, the U.S. Supreme Court issued its opinion for Quanta Computer et al. v. LG Electronics, Inc. ${ }^{1}$ The central issue of debate in this case was the doctrine of first sale patent exhaustion - whether, or more precisely when, the first sale of a product embodying patented technology by the patent holder limits in some way the patent rights, so that the patent holder cannot pursue any later purchasers for a license.

The issue of first sale seems simple enough on its face. Once the rights holder has sold a good embodying the invention covered by patent rights and received an economically warranted payment for those rights in return, that should be the end of the story. But intellectual property rights are rarely ever that simple and patent exhaustion is no exception as demonstrated by the fact that the Supreme Court saw fit to hear the Quanta case. To the contrary, a number of intricate legal and economic issues are at play in the first sale patent exhaustion doctrine. ${ }^{2}$ In this paper, we focus on the economic issues, taking a comprehensive

${ }^{1}$ Quanta Computer, Inc., et. al. v. LG Electronics, Inc., 553 U.S. _ _ 2008 U.S. LEXIS 4702 (June 9, 2008). The court found that patent exhaustion does indeed apply to method patents and thus applied to LG Electronics’ patents as embodied in Intel's components sold to Quanta Computers.

${ }^{2}$ For a sample of the debate that has continued after the Supreme Court's ruling in the case, see Jason McCammon, “The Validity of Conditional sales: Competing Views of Patent Exhaustion in Quanta Computer, Inc. v. LG Electronics, Inc, 128 S. Ct. 2109 (2008)”, Harvard Journal of Law \& Public Policy (2009); Sue Ann Mota, “The Doctrine of Patent Exhaustion: Not Exhausted by the Supreme Court in Quanta Computer v. LG Electronics in 2008”, SMU Science \& Technology Law Review (2008); Erin Austin, "Reconciling the Patent Exhaustion and Conditional Sale Doctrines in Light of Quanta Computer v. LG Electronics”, Cardozo Law Review (2009); John W. Osborne, “Justice Breyer's Bicycle and the Ignored Elephant of Patent Exhaustion: An Avoidable Collision in Quanta v. LGE”, The John Marshall Review of Intellectual Property (2007-08); and James W. Beard, “The Limits of Licensing: Quanta v. LGE and the New Doctrine of Simultaneous Exhaustion”, UCLA Journal of Law \& Technology (2008). 
view of the economic incentives and consequences of patent licensing as a means of shedding light on the application of the first sale exhaustion doctrine.

Two economic issues play a pivotal role in any evaluation of patent licensing: economically justified reward and efficiency. By an economically justified reward we mean the compensation a patent holder can expect to earn from the value of her patented technology without resort to the "hold up" of any ex post irreversible investments a licensee may make in the patented technology. As is well known, Congress enacted the Patent Act as a means of promoting "the progress of science and the useful arts." ${ }^{3}$ In other words, it is a temporary right to exclude others meant to provide incentives for inventors to create "useful" technological contributions for society. A patent is therefore a legal bargain with the government; it is not a natural entitlement. While patent law generally does not limit what a patent holder can charge for a license, in terms of inducing innovation the exclusion rights should offer the patent holder enough of a financial return to provide strong incentives to invest in frequently risky R\&D but not so much as to deprive consumers of the benefits of the innovation or to grind all subsequent follow-on innovation to a halt. ${ }^{4}$ Patent law, then, generally allows a patent holder to refuse to license altogether or to set the royalty rate and other licensing terms as she and the licensee collectively see fit.

${ }^{3}$ U.S. Constitution, article I, §8, clause 8.

${ }^{4}$ There is an extensive literature regarding the static as well as the dynamic effects of intellectual property rights. Regarding the first, the trade-off between patent length and breadth has been discussed in papers such as Klemperer (1990) and Gilbert and Shapiro (1990). The dynamic trade-offs are discussed by, e.g., Green and Scotchmer (1995). 
A simple example helps to clarify the economically justified reward point. Justice Breyer's analogy in the Quanta case $^{5}$ described firm X with a patent on a particular design for a bicycle pedal, which it licensed for a royalty to firm $\mathrm{Y}$ to use the design and attach the resulting pedal to a bike. Justice Breyer then reasoned that when Y sells the bike to a retail shop, patent holder $\mathrm{X}$ cannot also charge the retail shop a royalty for the pedal design. Nor, when the retail shop sells the bike to a consumer, can firm $\mathrm{X}$ chase the consumer down the street to get yet another royalty payment for the pedal design from the bicycle rider.

Implicit in Justice Breyer's example is the assumption that there exists one tradable right: the ability to manufacture the pedal design. When just one right is offered, any license that comes further down in the production chain can be considered double dipping - charging multiple times for the same right. ${ }^{6}$ However, patent rights can instead be thought of as a bundle of distinct rights, rather than as a single right. ${ }^{7}$ For instance, there is a right to exclude

\footnotetext{
5 "Imagine that I want to buy some bicycle pedals, so I go to the bicycle shop. These are fabulous pedals. The inventor has licensed somebody to make them, and he sold them to the shop, make and sell them. He sold them to the shop. I go buy the pedals. I put it in my bicycle. I start pedaling down the road.
}

Now, we don't want 19 patent inspectors chasing me or all of the other companies and there are many doctrines in the law designed to stop that. One is the equitable servitudes on chattel. Another is the exhaustion of a patent. And now you talk about implied license.

I would say, why does it make that much difference? What we're talking about here is whether after those pedals are sold to me under an agreement that the patent — you know, you have a right to sell them to me — why can’t I look at this as saying that patent is exhausted, the patent on the pedals and the patent for those bicycles insofar as that patent for the bicycles says I have a patent on inserting the pedal into a bicycle.” Justice Breyer, during oral arguments before the Supreme Court in Quanta v, LGE, 553 U.S_2008 (January 16, 2008).

6 “LGE was improperly attempting to obtain a double royalty”. Brief for Petitioners, Quanta at 10.

${ }^{7}$ This is an argument raised by MPEG LA LLC, as a friend of the court on behalf of LG Electronics. In particular, MPEG's brief stated that "The right to make and sell a device may have one value, while the right to 
others from using, a separate right to exclude others from making, and another right to exclude others from selling. These rights, in turn, can be split again, say into the right for others to sell in the Southern states versus the Northern states, or depending on the portfolio of patents, the right to sell in the U.S. versus Europe, Asia, or elsewhere.

That a patent can embody a bundle of rights leads us to the other pivotal economic concept in patent licensing: efficiency. Just as the legal bargain trades incentives to innovate (and to disclose that innovation in patent documentation) for a limited term of exclusivity, it is also in society's best interest to design intellectual property right rules so that patent holders have the incentives and the ability to license their inventions for broad implementation. It is mainly through diffusion and implementation that society reaps the benefits of a new invention. We therefore need to understand any impediments that might stand in the way of efficient licensing that would hinder the diffusion and implementation of useful innovations.

A better understanding of efficient licensing is the primary goal of this paper, because such an understanding is pivotal to evaluate the effects of the first sale patent exhaustion doctrine. The paper is structured in two parts. We start by showing that in a frictionless environment - understood as an environment where all information is public, firms are free to set prices for the goods they sell, and negotiation among firms jointly maximizes the benefits of the parties involved - the way in which a royalty rate is structured does not distort competition nor diminish social welfare. Thus, in this ideal setting the patent holder cannot use the royalty structure in an opportunistic way to affect market structure or extract Respondent, Quanta at 24. See also, Epstein (2007); Kieff (2008). 
additional rents from downstream competitors or consumers. In the second part of the paper, we discuss the impact of some of the frictions that are, in reality, typically present in technology markets. Even in this less-than-ideal environment, we show that it is still often in the interest of both the patent holder and society as a whole to split the total royalty burden among different parties in the production process - contrary to the arguments the Supreme Court laid out in Quanta. ${ }^{8}$

For the first part, we start by assuming a Pareto optimal bargaining process between upstream and downstream producers. That is, we assume that the negotiation exhausts all possible gains to both parties so that no money is left on the table. We find that different assignments of the royalty burden have no impact on social welfare and that it is instead the aggregate royalty per unit sold in the downstream market that matters. We illustrate this general principle, which we denote as royalty allocation neutrality, first by means of example. We show that neutrality operates in typical vertical relations (as in Justice Breyer's bike pedal example above) regardless of the market power the upstream manufacturer might have (e.g., the firm attaching the pedal to the bike), the necessary investments for production, or the possibility that the upstream firm might also integrate a downstream production unit (i.e., that the firm attaching the pedal to the bicycle might also own a bike shop).

To provide intuition for this result, consider a situation where a patent holder charges a royalty to both an upstream and downstream producer. The upstream producer sells its component, which incorporates the patented technology, to the downstream producer, who then sells the end good to consumers. What happens if the patent holder shifts part of the

\footnotetext{
${ }^{8}$ In both parts we are evaluating ex ante licensing negotiations, before potential licensees have begun to make any products that might implement the patented technology and thus before any irreversible investments
} 
royalty burden upstream, raising the upstream royalty but lowering the downstream one so as to leave the aggregate royalty unchanged? It turns out that the intermediate price the upstream manufacturer charges the downstream party will rise to accommodate the increase in costs that the upstream manufacturer suffers. In other words, the upstream manufacturer passes on the additional royalty payment, exactly offsetting the cost-savings enjoyed by the downstream producer from the lower royalty rate. This pass-through element is the fundamental insight of Ronald Coase in his famous theorem on the reallocation of costs to achieve an economically efficient outcome. ${ }^{9}$ The reallocation argument only holds, though, if there are no transaction costs or roadblocks in the way of passing costs down the chain.

In many relevant instances, of course, roadblocks or transaction costs are important. Therefore, we devote the second part of the paper to discussing some of the likely implications of transaction costs on the optimal allocation of royalties. In particular, we discuss two such frictions: the existence of private information and the constraints firms may face in pricing the final good (for example, if the upstream producer cannot price discriminate among different downstream buyers).

To see how frictions can alter the analysis, consider the case of private information. Royalty payments are typically predicated on the amount of a good actually sold in the marketplace. The literature has proposed many explanations for the predominance of these contracts, mainly related to private information. ${ }^{10}$ As opposed to the sale of a physical good

have been made.

9 See Coase (1960).

10 For example, Beggs (1992) and Macho-Stadler and Pérez Castrillo (1996) study models in which the innovator uses a combination of royalties and fees to separate licensees with different cost reductions. Other papers show that royalties can be a signal of the quality of the innovation (Gallini and Wright (1990))) or a 
where total sales can be estimated from the units of the input transferred, intellectual property allows for an unlimited number of units. That means patent holders must be able to verify the quantities sold. It also means that licensees can have incentives to underreport sales in order to reduce their royalty payments. In this case, enforcing the patent contract is more complicated and the patent holder may not, depending on the precise state of the legal rule relating to the first sale doctrine of patent law, contract ahead, where pass-through royalties and terms for the next level of production are dictated in the first. Instead, it may be optimal for the patent holder to individually contract with multiple layers in the production chain, charging each link a partial royalty (as compared to the aggregate one that would have maintained under royalty allocation neutrality). The lower individual rates reduce licensees' incentives to underreport royalty payments owed and the multiple licenses provide several check points for verifying quantities sold.

Taking account of the arguments made in relation to the Quanta case, we also consider whether a patent holder would have incentives to “double dip”, interpreting it in our model as deceiving the upstream and downstream manufacturers into paying "excessive” aggregate royalty payments. In order to raise the aggregate payment, when negotiating with the upstream firm the patent holder would need to pretend that the royalty downstream was lower than it really is in order to charge a higher royalty upstream, and vice versa with the downstream firm. Our results, however, point to precisely the opposite result. That is, contrary to the concerns raised during the Quanta case, ${ }^{11}$ the patent holder is unable to benefit

response to the existence of moral hazard (Choi (2001), Jensen and Thursby (2001)). The specification of royalties might also be dictated by risk-sharing purposes (Bouquet et al. (1998)).

\footnotetext{
${ }^{11}$ Supra note 6 .
} 
from overcharging or double dipping under these circumstances. The reason is that increases in the total royalty that could be obtained from deception would also lead to an increase in the price of the final product, but the resulting decrease in sales would outweigh the price increase, leading to a decrease in royalty earnings for the patent holder.

Overall, the reading from our analysis is that in most cases the division of the royalty among the different firms in the production process has no impact on social welfare. Different allocations will be more or less desirable inasmuch as the total royalty they represent is higher or lower than what is socially desirable. Charging just one versus charging multiple parties is not the pivotal element for social welfare. In fact, in the presence of frictions, the way the total burden is split is likely to reflect the cheapest and most convenient way to implement licensing, which is bound to differ across firms, industries, and sectors of the economy. In other words, charging multiple parties might be crucial to maintaining both economically justified rewards and efficient licensing. Thus, either with or without frictions, our findings suggest that in most circumstances a strict application of first sale patent exhaustion could create economic inefficiencies. While we recognize that one of the benefits stemming from first sale patent exhaustion is the certainty that later users of a product will not be sought after for a license, if this was an important risk it could easily be addressed by using patent exhaustion as the presumed or "default” (but not mandatory) rule. In that case, first sale patent exhaustion would be overturned through explicit clauses of patent licensing. If the license contract did not specify limitations or any subset of rights that are not passed through to the licensee's customers, then patent exhaustion would apply; otherwise it would not. $^{12}$

\footnotetext{
${ }^{12}$ Our layman's read of the Supreme Court's decision in Quanta is that the Court did not rule out this result.
} 
The paper is organized as follows. Section 2 offers some examples of royalty allocation neutrality to clarify our ideas. Section 3 then presents the general principles underlying royalty allocation neutrality. Section 4 considers the implications of dropping the assumptions required to obtain royalty allocation neutrality while Section 5 addresses the potential for double dipping. We conclude in Section 6.

\section{Some Examples of Royalty Allocation Neutrality}

In the introduction we claim that royalty allocation neutrality is a general property holding in markets where a patent holder can charge royalties to firms that operate in different stages of the production process. In this section, we discuss several examples that provide intuition on the mechanism at work. In the next section we discuss the general model and the assumptions behind the royalty allocation neutrality result.

To illustrate our analysis, we introduce the following generic market structure. Consider a market where three firms operate: a downstream producer $D$ sells a final product to consumers according to a demand function $D(p)$; an upstream producer $U$ sells a necessary input required by $D$ to create the final product ( $U$ might also sell a product in the final market); and a patent holder $H$ that can license its patent for a cost-reducing innovation $P$ to both $D$ and $U$. For every unit of the final good that $D$ produces, it needs one unit of $U$ 's intermediate good, for which $U$ charges $s$. The total cost of producing the final good without

The decision appears to leave open the question of contractual restrictions, saying only in footnote 7 that "We note that the authorized nature of the sale to Quanta does not necessarily limit LGE's other contract rights. LGE's complaint does not include a breach-of-contract claim, and we express no opinion on whether contract damages might be available even though exhaustion operates to eliminate past damages.” Quanta Computer, Inc. v. LG Electronics, Inc., 128 S.Ct. 2109 (2008). 
the patented technology is $c_{0}$. If the final good is produced with the patented technology, the total marginal cost falls to $c<c_{0} \cdot{ }^{13}$ In exchange for a license to use $P$, the patent holder $H$ demands a royalty $r_{U}$ from the upstream input producer $U$ and a royalty $r_{D}$ from the downstream producer $D .{ }^{14}$ The first example describes the simplest scenario.

Example 1 (Bilateral Negotiation): Suppose that the intermediate input price $s$ is the result of negotiation between the upstream monopolist producer $U$ and the downstream monopolist $D .{ }^{15}$ Furthermore, this negotiation is carried out following Nash Bargaining, where $U$ has bargaining power $\beta$ while $D$ has the reciprocal power $1-\beta$. For simplicity, we postulate a linear demand function $D(p)=1-p$, although the result applies generally.

The timing is as follows. The patent holder $H$ first chooses royalties $r_{U}$ and $r_{D}$. The upstream and downstream firms then bargain over $s$ and then the downstream producer chooses the final price $p$.

Starting from the last stage, $D$ chooses the price according to its profit function, $\max _{p}\left(p-\left(c+r_{D}+s\right)\right) D(p)$, which is simply the price net of costs multiplied by quantity demanded, and which results in the profit maximizing monopolist price $p^{M}(s)=\left(1+c+r_{D}+s\right) / 2$. With this price, the upstream producer obtains profits $\Pi_{U}(s)=\left(s-r_{U}\right) D\left(p^{M}(s)\right)$, which again is simply the upstream price net of upstream costs

${ }^{13}$ Throughout the paper we will assume that $c$ is sufficiently small so that even when the upstream producer charges its monopoly price, production with the alternative technology is unprofitable. In example 1 , however, we show that the results do not hinge on this simplifying assumption.

${ }^{14}$ We abstract from all other license terms, but in reality most license contracts contain a host of provisions of which royalty rates are but one.

${ }^{15}$ Since $D$ is the only downstream producer, it is also a monopsonist buyer for $U$ 's good. 
multiplied by quantity demanded at the given downstream price. Notice that without loss of generality we have normalized the cost of the upstream producer to 0 .

Working our way up the production chain, the equilibrium price for the upstream component $s$ is then determined by maximizing the function $\max _{s} \Pi_{U}(s)^{\beta} \Pi_{D}(s)^{1-\beta}$, which yields the optimal intermediate price $s^{*}=\left(\beta\left(1-c-r_{D}\right)+(2-\beta) r_{U}\right) / 2$. This optimal intermediate price is increasing in the bargaining power of the upstream producer in the relevant range (i.e., the higher $\beta$ is, the higher $s^{*}$ ). Note that to the extent that bargaining power is positive, $\beta>0$, then the optimal intermediate price will strictly exceed the upstream royalty rate $\left(s^{*}>r_{U}\right)$, resulting in the familiar problem of double marginalization. ${ }^{16}$ Furthermore, $s *$ increases when the downstream royalty $\left(r_{D}\right)$ decreases or when the upstream royalty $\left(r_{U}\right)$ increases. This last result stems from the pass-through effect discussed in the introduction, which, as we will now show, leads to our neutrality result.

Replacing $p^{M}$ and using the demand function we obtain the optimal quantity sold as $q^{*}=\frac{(2-\beta)\left(1-c-r_{U}-r_{D}\right)}{4}$. As the equation shows, the optimal quantity is decreasing in the total royalty, $r_{U}+r_{D}$, which operates to increase the marginal cost of the downstream firm. Optimal quantity is also decreasing in the bargaining power of the upstream producer, $\beta$.

Profits for the patent holder $H$ can be written as $\Pi_{H}=\left(r_{U}+r_{D}\right) q^{*}$ where $q^{*}$ is, as observed before, a function of only the sum of $r_{D}$ and $r_{U}$. That is, the distribution of the

\footnotetext{
${ }^{16}$ Spengler (1950)
} 
royalties between $U$ and $D$ is neutral from the patent holder's perspective, only their sum matters. ${ }^{17}$ In fact, it is easy to verify that the optimal sum of royalties is characterized by

$$
\text { (1.1) } r_{u}^{*}+r_{D}^{*}=\frac{1-c}{2}
$$

Finally, notice that the previous computations assume that $s *$ is such that the downstream producer prefers not to buy the upstream product based on the alternative technology, competitively priced at $s_{0}=c_{0}$. In particular, the downstream firm will buy the alternative input if $s^{*}>c_{0}-c-r_{D}$. If the intermediate price that results from the Nash bargaining does not satisfy this constraint, firms will optimally set $\bar{s}=c_{0}-c-r_{D}$. Replacing in the final quantity sold we obtain $q^{*}=\frac{(2-\beta)\left(1-c_{0}\right)}{4}$. Hence, the patent holder will maximize profits

$$
\begin{aligned}
& \max \left(r_{U}+r_{D}\right) q^{*} \\
& \text { s.t. } r_{U} \leq \bar{s}=c_{0}-c-r_{D}
\end{aligned}
$$

where the first part of the constraint ensures that the upstream producer obtains non-negative profits. It is easy to see that the optimal combination of royalties is equal to the production cost savings, so that $r_{U}+r_{D}=c_{0}-c$, which, again, only depends on the sum of royalties. ${ }^{18}$

\footnotetext{
${ }^{17}$ As pointed out before, these results generalize to other demand functions. For example, if demand is isoelastic with elasticity $\eta$, the equilibrium intermediate price becomes $s^{*}=\left(\beta c+\beta r_{D}+(\eta+\beta-1) r_{U}\right) /(\eta-1)$ and downstream quantity $q^{*}=\left(\eta \frac{\beta c+(\eta+\beta-1)\left(r_{U}+r_{D}\right)}{(\eta-1)^{2}}\right)^{-\eta}$, which, again, only depends on the sum of the royalties.

${ }^{18}$ If there are recurring costs to licensing, those would need to be included. Further, we assume here that the patent holder's initial investments in $R \& D$ are covered by the aggregate royalty rate.
} 
Several things are worth pointing out from the previous example. In the negotiation process between the upstream and the downstream producer, the intermediate price $s$ exhausts the entire surplus that both producers can achieve. In other words, the Nash Bargaining solution guarantees efficiency of the outcome. The solution divides surplus depending on how the bargaining power is allocated.

The bargaining power of each of the two parties is independent of the way that royalties are allocated. In this way we rule out, for example, the unrealistic possibility that the upstream producer is the one choosing the intermediate price $s(\beta=1)$ for some values of $r_{D}$ and $r_{U}$ whereas the downstream producer chooses the price for other values $(\beta=0)$. Our setup nonetheless allows for the possibility, for instance, that the upstream producer is limited in its pricing choice by the presence of an alternative input technology.

Finally, it is important to note that, although the intermediate price $s$ leads to an efficient allocation for the coalition between the upstream and the downstream producer, the price chosen in the downstream market does not necessarily accomplish the same goal. In fact, in the previous example, the price that maximizes profits where both the upstream and downstream firms are integrated corresponds to $p^{M}=\left(1+c+r_{D}+r_{U}\right) / 2$. When firms are separate, however, the double-marginalization distortion mentioned above leads to a higher final price. This result would suggest that charging all of the royalty downstream could benefit the patent holder. As it turns out, however, this conjecture is not true, since the intermediate price $s$ adjusts as the upstream royalty rate changes. So, an important lesson is that double-marginalization distortions are unrelated to the contract that the patent holder might be able to offer and derive solely from the relationship between $U$ and $D$. 
Note that the result regarding double marginalization does not hold if the patent holder could charge a two-part tariff, consisting of a royalty rate and a fixed fee. Even though the same royalty allocation neutrality result would hold, because the patent holder could extract its rents through a fixed fee that does not affect marginal quantity decisions, the license could undo the double-marginalization arising from the relationship between the upstream and the downstream producer by charging a negative royalty rate upstream. In that case the downstream monopoly price (which is lower than the price under double marginalization) would be attained, downstream quantities would be higher, the upstream producer would be compensated for its inability to charge a margin through the negative royalty rate, and the patent holder would be compensated through the corresponding fixed fees. That said, while theoretically possible, negative royalty rates seem unrealistic.

Example 2 (Raising Rival's Cost): Suppose that in the previous example the upstream producer, firm $U$, also produces a substitute good to the one sold by the downstream firm $D$. It is well-known that the upstream producer might raise the price of the input of the downstream competitor as a way of increasing the benefit $U$ gains from the sale of its

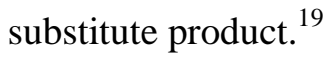

To simplify the exposition and make the case for the raising-rival's-cost argument more obvious, ${ }^{20}$ we assume that the upstream producer has all the bargaining power, $\beta=1$,

\footnotetext{
${ }^{19}$ See, for example, Salop and Scheffman (1987); Ordover, Saloner, and Salop (1990); and Schmidt (2006).

${ }^{20}$ This term was coined by Salop and Scheffman (1983). When this increase in costs prices the otherwise efficient competitor product out of the market it is usually referred as vertical price squeeze. For examples of price squeezing, see linkLine Comm’n v. See Pacific Bell Telephone Co., 503 F.3d 876 (9th Cir. 2007); CavalierTelephone, LLC v. Verizon Virginia, Inc., 330 F.3d 176 (4th Cir. 2003); Covad Communications Co. v. BellSouth Corp., 374 F.3d 1044 (11th Cir. 2004); Eastman Kodak Co. v. Image Technical Serv., 504 U.S. 451
} (1992). 
although the result would hold for a general $\beta$. Both downstream competitors face a symmetric downstream demand $D_{i}\left(p_{i}, p_{j}\right)=1-p_{i}-d p_{j}$ for $i, j=U, D$ and $i \neq j$, where the parameter $d \in(0,1)$ measures the degree of substitution between the two products. ${ }^{21}$ The upstream producer sells the final good at a price $p_{U}$ and incurs a marginal cost of production $c_{U}=c+r_{D}+r_{U}$. Note that the cost of the upstream producer includes both $r_{U}+r_{D}$ because this firm is vertically integrated.

We adapt the timing of the model in the natural way. First, the patent holder decides the royalties it charges to both upstream and downstream producers. Second, the upstream producer chooses the price for the intermediate input $s$ and, finally, both manufacturing firms simultaneously choose end market prices, $p_{U}$ and $p_{D}$.

We start from the final stage of the game. Both firms choose prices to maximize profits. In particular, profits for the upstream producer correspond to

$$
(1.2) \Pi_{U}\left(s, p_{D}\right)=\max _{P_{D}}\left(s-r_{U}\right) D_{D}\left(p_{D}, p_{U}\right)+\left(p_{U}-c_{U}\right) D_{U}\left(p_{U}, p_{D}\right)
$$

Notice that by choosing the price downstream $\left(p_{D)}\right.$ the firm $U$ also affects how much it receives from its downstream competitor through the units it sells in the final good market. Solving this expression we can observe that the equilibrium in this last stage leads to prices $p_{U}^{*}$ and $p_{D}^{*}$, both of which increase as royalties $\left(r_{U}, r_{D}\right)$, the intermediate price $(s)$, the degree of substitution $(d)$ or the cost of production $(c)$ increases.

If we replace the prices in equation (1.2) above with their formulae and then maximize with respect to the intermediate good price $s$, we are able to obtain the optimal intermediate

\footnotetext{
${ }^{21}$ All the results carry over to the case where products are complements, represented by $d<0$.
} 
price $s^{*}\left(r_{U}, r_{D}, c, d\right)$, which decreases as either $c$ or $r_{D}$ increases and which increases as $r_{U}$ increases, if substitution $d$ is sufficiently large. Furthermore, it can be shown that $s^{*}+r_{D}$ depends only on aggregate royalties, $r_{U}+r_{D}$, not on either of the royalties individually.

Using the previous result, we obtain that the marginal cost of the downstream producer is only a function of the sum of the royalties, in the same way that for the upstream integrated firm the production of a unit entails a royalty payment of $r_{U}+r_{D}$. It is immediate, therefore, that the equilibrium quantities $q_{1}^{*}=D_{1}\left(p_{1}^{*}, p_{2}^{*}\right)$ and $q_{2}^{*}=D_{2}\left(p_{2}^{*}, p_{1}^{*}\right)$ are a function only of the sum of the royalties. Since, profits for the patent holder arise in this case from total royalties multiplied by total quantitites,

$$
\Pi_{H}=\max _{r_{U}, r_{D}}\left(r_{U}+r_{D}\right)\left(q_{U}^{*}+q_{D}^{*}\right)
$$

it must be the case that only the sum of the royalties matters. In particular, it can be shown that profits are maximized if the sum of royalties is equal to a particular combination of costs and substitution, given by

$$
r_{U}^{*}+r_{D}^{*}=\frac{1-c(1-d)}{2(1-d)}
$$

Notice that the sum of these royalties falls as the marginal cost of production $c$ falls and as the degree of product differentiation falls (or in other words, the sum of royalties rises as the degree of substitution $d$ increases). Of course, when products are independent $d=0$ and this expression corresponds to the one given by (1.1).

The previous example shows why the principle of royalty allocation neutrality holds even in markets where upstream manufacturers are vertically integrated and there are a number of 
downstream competitors. Even when the patent holder charges a different combination of royalties up and downstream, the upstream manufacturer responds by changing the wholesale price $s$ leaving the total input cost for the final product, $s^{*}+r_{D}$, unchanged. It is in this sense that we say the aggregate royalty is the key variable, not the individual rates.

Example 3 (Double-Sided Moral Hazard): Consider next a model where effort plays a role in product success. Suppose that in the first example, before the upstream and downstream producers bargain over the price $s$ at which they will exchange the input in the final production process, both firms need to incur in an investment. The cost of this investment is $e_{i}$ (for $i=U, D$ ) and it leads to a probability of success, $P\left(e_{U}\right) P\left(e_{D}\right)$, where $P$ is increasing and concave in its argument. ${ }^{22}$

Net profits for the upstream and downstream producer are equal to the probability of success multiplied by the normal profit (which is a function of the royalty rates paid) minus the effort investment. This can be written as, respectively for the upstream and the downstream firm,

$$
\begin{aligned}
& \Pi_{U}\left(r_{U}+r_{D}\right)=\max _{e_{U}} P\left(e_{U}\right) P\left(e_{D}\right) \pi_{U}\left(r_{U}+r_{D}\right)-e_{U}, \\
& \Pi_{D}\left(r_{U}+r_{D}\right)=\max _{e_{D}} P\left(e_{U}\right) P\left(e_{D}\right) \pi_{D}\left(r_{U}+r_{D}\right)-e_{D} .
\end{aligned}
$$

The two profit functions $\pi_{U}\left(r_{U}+r_{D}\right)$ and $\pi_{D}\left(r_{U}+r_{D}\right)$ are the profits obtained when the project is successful. Recall that these two equations were shown above to depend only on the sum of the royalties. It is immediate, then, that the effort exerted by the upstream and downstream producer is independent of the way the royalties are allocated among them and again only their sum matters. Of course, the same result would arise for more general forms of

\footnotetext{
${ }^{22}$ Lafontaine (1992) shows that double-sided moral hazard characterizes the ralations between franchisees
} 
complementarity between the effort of the upstream and the downstream producer or even in the case in which this complementarity does not exist.

Finally, notice that this setup also includes the case where only the investment of one of the parties is required, as it would correspond to $e^{*}, i=0$ for the other one.

This last example illustrates why the neutrality principle still holds in the presence of a moral hazard. As long as the Nash Bargaining process works to maximize the two manufacturers' joint profits, there is no role for the patent holder $H$ to manage effort levels by manipulating the royalty rates. These few examples lead us to a general principle of royalty allocation neutrality, which we explain next.

\section{The General Principle of Royalty Allocation Neutrality}

The previous examples, although quite different in nature, share two common features that turn out to be crucial for royalty allocation neutrality. The first is the fact that different allocations of individual royalties do not lead to changes in the overall profits attainable by a coalition between the upstream and downstream producer. In other words, the same sum of profits can be achieved by appropriately changing the intermediate good's price $s$ for different divisions of the same total royalty burden.

The second feature has to do with the way the total surplus is allocated among the parties. In the previous three examples, the allocation of the surplus is efficient. Using the Coase Theorem, and its famous insight on the reallocation of costs, it is immediate that the total final quantity should be independent of who is paying the cost of this production. ${ }^{23}$ Most

and franchisors.

${ }^{23}$ Notice that we are making use of the so-called "strong” version of the Coase Theorem that states not only that the outcome is efficient but also invariant to the assignment of property rights. Here, the theorem applies to 
important for our purposes is the fact that the rule governing the allocation of the surplus is independent of how the royalties are allocated. As pointed out before, however, if the upstream producer had price setting power for some values of $r_{U}$ and $r_{D}$ but not for others, the results would certainly vary. We find this scenario unlikely though.

Figure 1 illustrates these two features. The solid line corresponds to all the possible allocations of profits among the upstream and downstream producers. These allocations are spawned by the different values of $s$. Profits for the upstream producer range from $\Pi M, U$, which are the profits obtained when it has all the bargaining power, to 0, which can be obtained when $s=r_{U}$ or else when $s$ is so high that the quantity sold is 0 . Notice that the first case corresponds to the maximum profits that the downstream producer can achieve (in the figure labeled as $\Pi M, D$ ). In the other case both profits are 0 . Efficient negotiation rules out all values of $s$ higher than the monopoly one, which generate outcomes in the region where $\Pi_{D}<\underline{\Pi}_{D}$

the relationship between the upstream and the downstream firm. Because the negotiation process leads to an efficient outcome that divides the total surplus according to the bargaining power of each of the parties, the final allocation only depends on the total royalty payment and not on how the patent holder structures these payments among the two firms. The price of the input adjusts to any change in royalty structure, leading to an invariant allocation (in this case, the quantity being produced). 
Figure 1: Division of profits for a given royalty sum $r_{U}+r_{D}$

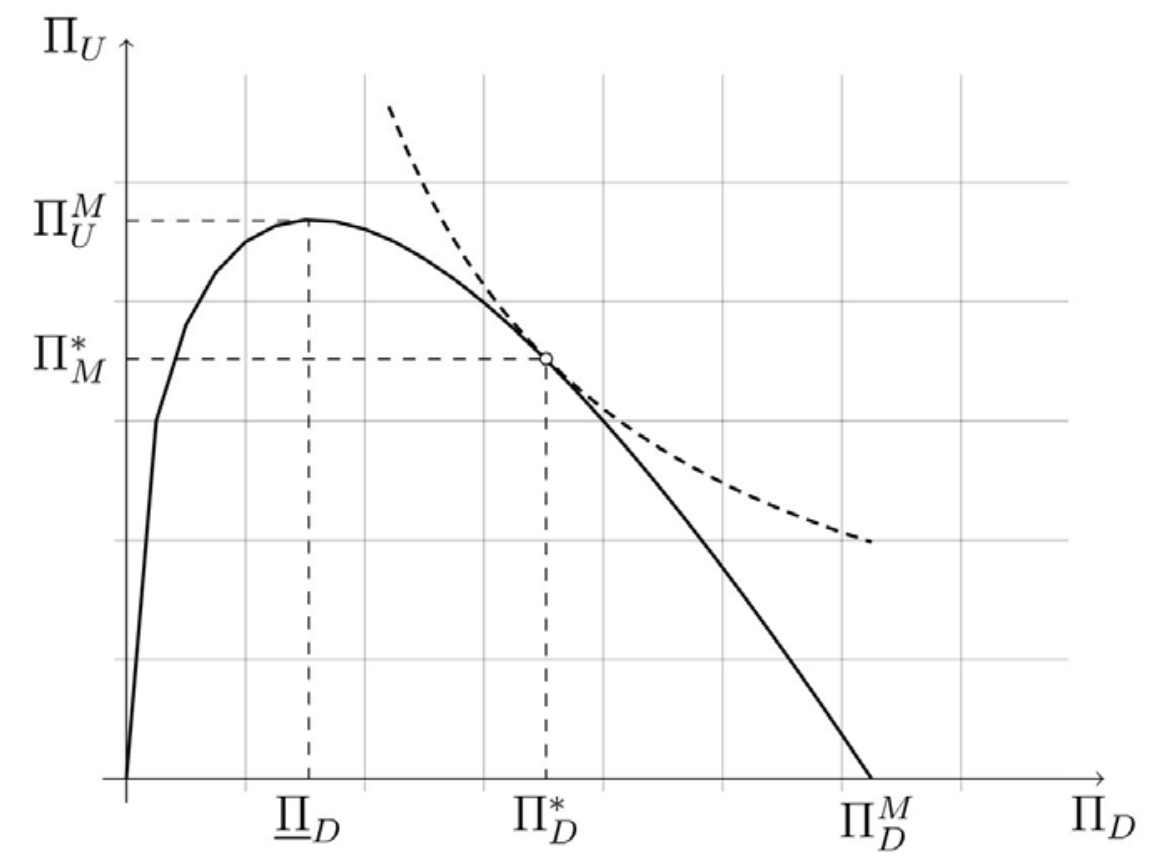

It is important to notice that for a given level of $r_{U}+r_{D}$ this set is unchanged regardless of the way the individual royalties are allocated. In other words, if this set arises for a certain combination ¡Error!, it will also arise for the combination $\left(r_{U}^{\prime}, r_{D}{ }^{\prime}\right)$ as long as the sum is the same (i.e., $r_{U}^{\prime}=r_{U}+\varepsilon$ and $r_{D}^{\prime}=r_{D}-\varepsilon$ ) and the wholesale price $s$ is simply replaced by $s^{\prime}=s+\varepsilon$.

The dashed curve in Figure 1 shows the objective function that the Nash Bargaining solution maximizes. The point at which both curves are tangent determines the outcome. A higher value of $\beta$, meaning more bargaining power for the upstream producer $U$, leads to a higher value on the solid line, getting closer to the upstream monopoly allocation ¡Error!, achieved when $\beta=1$. In other words, when the upstream firm behaves as a monopolist it 
charges an intermediate price sufficiently high so as to maximize its profits. Of course, if $s$ is too large, profits for both parties decrease. More bargaining power for the downstream producer (a lower $\beta$ ) generates allocations that tend towards downstream monopoly $\left(0, \Pi_{D}^{M}\right)$, achieved only when $\beta=0$. Clearly, for the allocation of royalties to be neutral we require that bargaining power $\beta$ does not depend on either royalty rate $\left(r_{U}\right.$ or $\left.r_{D}\right)$, or alternatively that $\beta$ depends only on their sum, but this independence strikes us as a natural assumption.

The previous intuitions allow us to state the following general result (proven in appendix A).

Proposition 1 (Royalty Allocation Neutrality): If the final price of each good is increasing in its marginal costs and the negotiation between the upstream and downstream producers has the following properties:

1. the outcome is Pareto optimal for the coalition, and

2. expansions of feasible combinations of profits cannot make any of the parties worse off,

then, the final allocation depends only on the sum of the royalty charged for the upstream and the downstream producer of each good.

Notice that our previous examples naturally satisfy these conditions. The Nash bargaining solution that is assumed (cases where the upstream firm acts as a monopolist or the downstream firm as a monopsonist are particular examples) always leads to efficient outcomes. Furthermore, the price of the intermediate good is such that each firm's profits are increasing in the total surplus divided between the upstream and the downstream firms according to the bargaining weight $\beta$. 
The proof developed in the appendix is based on the fact that under the conditions stated in the text of this proposition, the upstream producer adapts the intermediate price, as shown in example 2, to exactly offset the impact that changes in the distribution of the total royalty have on the marginal cost perceived by the downstream producer. In other words, the upstream producer chooses $s^{*}$ so that the sum $s^{*}+r_{D}$ depends only on the sum of the royalties. Thus, the final price and the total number of units sold will change only if the sum of the royalties change.

\section{Deviations from Royalty Allocation Neutrality}

As we explained in the previous section, royalty allocation neutrality hinges on the flexibility that the upstream and downstream producers have to adjust the wholesale price $s$ in order to compensate for different royalty allocations by the patent holder. Implicit in this argument is the idea that negotiation is frictionless and its outcome cannot be improved upon. But oftentimes it is not realistic to assume that negotiation will lead to a Pareto optimal outcome; the quest for individual profits might destroy overall value. Similarly, Pareto efficiency might break down due to technological or institutional constraints that may limit the pricing flexibility, for example, of the upstream producer vis-à-vis the patent holder. In those cases, $s$ cannot be adjusted at will to maintain joint profit maximization. In this section we elaborate on these two reasons for royalty allocation neutrality to fail, and we illustrate them with variations of example 1.

Regarding the first case, we focus on information asymmetries that are likely to appear and that might affect contract enforcement. ${ }^{24}$ In particular, if a patent license contract

\footnotetext{
${ }^{24}$ As LG Electronics argued in the case, “petitioners' [Quanta] approach would demand that the full and
} 
includes a percentage royalty rate or a per-unit fee -terms that are used commonly in patent licensing - then the patent holder has a strong interest in setting the base for the royalty calculations on observable or verifiable quantities that licensed firms sell. Ambiguity over the relevant quantities sold, and hence over the basis for royalty payments, is an important difference between the licensing of intellectual property and the sale of a physical input. In the bike pedal example discussed in the introduction, if the designer were also the only manufacturer, the quantities sold in the final market (number of bicycles) would be easily inferred from the number of pedals sold. Once the pedal designer chooses not to manufacture itself, but instead to license its intellectual property to an upstream (pedal) manufacturer, it loses control over the number of units sold.

Oftentimes the relevant quantity sold is not easily verifiable. Centralized exchanges are not very common and when they do exist they only channel a limited proportion of the total units sold. ${ }^{25}$ The bulk of transactions are carried out using private long-term contracts. But even with established long-term contracts, for many technology products the sale of intermediate components is difficult to monitor. In fact, this is an important concern for many firms and has triggered the development of tracking systems for individual units (or boxes) being sold for licensing purposes. For example, one firm instituted a license whereby a box can only be shipped if proof of the license is displayed on the outside. ${ }^{26}$

final value of these patents be determined at a single point in the distribution chain, where the relevant information simply does not exist.” Brief of respondent, Quanta at 32.

${ }^{19}$ See Brown-Hruska et al. (1999). See also Bias (1983).

${ }^{26}$ Such a per batch licensing system has been introduced by Phillips (who dubbed the program VEEZA) in place of its previous CD-R Disc Patent License Agreements. With VEEZA, a separate license is obtained for each shipment. The shipments are marked with a unique code that signals to the traders and retailers that the 
Even where monitoring sales is relatively easier, it can be difficult to identify the exact goods covered by a license. Manufacturers often sell a myriad of similar yet different products, so determining which do and which do not incorporate the intellectual property licensed can be difficult and expensive. This is especially problematic for complex high technology products, such as goods that incorporate multiple semiconductor chips and thus tend to rely on hundreds, if not thousands, of patents. ${ }^{27}$

As a result of these complications, when the relevant quantities are not directly observable the patent holder may choose to monitor one or several stages of the production process to improve information collection. For example, if monitoring is costly, it may make sense to concentrate effort in the stage where this cost is lowest. The cost of monitoring the level of production might be different depending on the number of players in the market or the closeness to the final consumer. In particular, in markets where upstream prices are obtained as the result of private negotiations but downstream prices are posted and publicly available, monitoring is likely to take place in this last stage.

More interestingly, the patent holder might often want to charge royalties at the different stages of the production chain if splitting fees in this fashion allows the firm to obtain additional estimates of the quantity sold that complement the direct observation gathered through monitoring. Alternatively, lower royalty rates to each stage might increase the odds of obtaining accurate information (i.e., reduce the incentives of licensees to under-report). Timing might play a role as well if negotiations with a downstream producer, say, can take

merchandise is licensed. See Philips Intellectual Property \& Standards, Licensing (available at https://www.ip.philips.com/services/?module=IpsLicenseProgram\&command=View\&id=20\&part=7).

${ }^{27}$ See, Shapiro (2000) p. 125. 
place at a later date, when the downstream firm knows its needs better, whereas at the time of negotiations with the upstream producer the downstream needs would need to be forecasted.

Furthermore, the patent holder may prefer a spread allocation of the royalty burden due to the differences in the cost of enforcing a licensing contract. In case of a dispute, say because the licensee refuses to fulfill its payment obligations, the patent holder has different leverage depending on the characteristics of the licensee. Injunctions might be more effective against those firms for which the product incorporating the patent is highly profitable. This threat alone might often be enough to allow the proper enforcement of the contract. As a result, if enforcement is an important concern, the patent holder may want to shift the royalty burden towards those stages in which licensee competition is weaker and the price margin is higher. In technology markets, these high-margin stages are often the ones closest to the final consumer, where product differentiation makes competition less fierce. The next example outlines many of the forces that we have discussed so far.

Example 4 (Asymmetric Information): Consider the model presented in example 1, and for simplicity assume that $\beta=1$ so that the upstream producer has all the bargaining power. Assume that the patent holder does not observe the final quantity sold, which is only observed by the upstream and downstream producers. The patent holder knows, however, that the demand for this product will be high (represented as $D(p)=1-p$ ) with probability $v$ and low (represented as $D(p)=0$ ) with probability $1-v$.

High demand corresponds to our original example 1, thus the upstream and downstream firms will operate under the same strategy as they did there. Denote their profits, gross of royalty payments, as $\pi_{U}$ and $\pi_{D}$. When demand is zero, the prices chosen will be irrelevant and profits will be 0 . The patent holder, however, absent a monitoring mechanism cannot 
distinguish between these two outcomes and thus will never obtain any royalty payments, since both firms will claim that the low realization of the demand occurred in order to avoid paying royalties. Profits for the patent holder are thus 0 .

Suppose now that the patent holder has access to a monitoring technology, such that spending amounts $k_{U}$ and $k_{D}$ allows him to verify through the upstream or the downstream stage, respectively, which realization of the demand occurred. Clearly, in this case, the patent holder will maximize profits by monitoring only the stage of the process where this cost is lowest.

Alternatively, the patent holder might be able to impose a cost on firms misrepresenting their sales figures. For illustration purposes we assume that this cost is fixed and equal to $F>$ 0 . The patent holder can use this threat to elicit the private information that licensee firms possess.

In particular, consider the following contract that the patent holder can establish. A royalty is charged in both stages of the process. The patent holder requires each firm to declare the number of units being sold. If both firms make the same assessment, the upstream and downstream firm pay a per unit royalty $r_{U}$ and $r_{D}$. If firms differ in their assessments, the firm that has declared a demand of 0 is fined an amount $F$. The other firm pays a royalty for the units it declares to have sold. The payoff matrix when the high demand realization has occurred reads as shown in Table 1. 
Table 1. Payoff Matrix

D

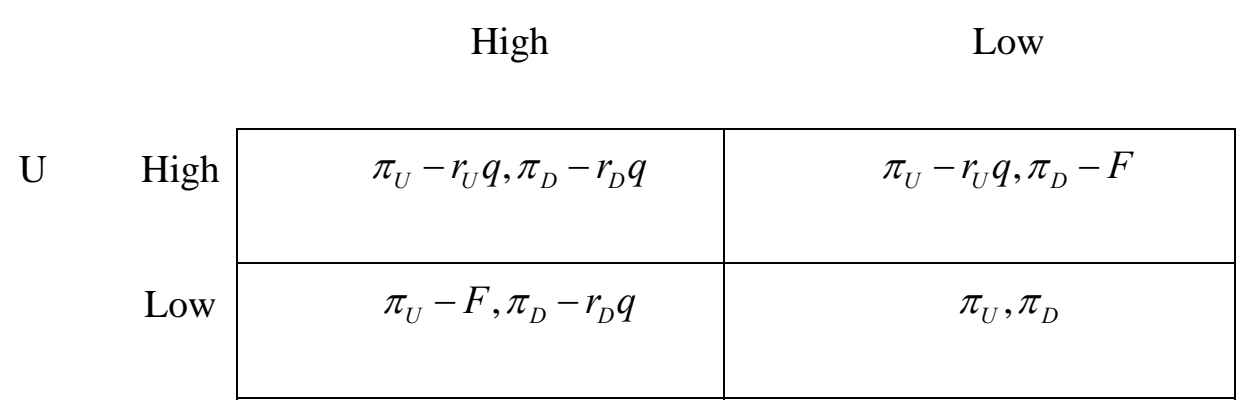

Notice that with the existence of fines, declaring that demand was high becomes a Nash Equilibrium as long as $F$ is sufficiently high. In cases where charging the total royalty in one of the stages does not satisfy these constraints, the allocation that splits it in the different stages may prevent firms from misrepresenting their sales. ${ }^{28}$

The second source of friction that might break royalty allocation neutrality is related to technological or institutional limits in the way that the intermediate price may adjust to changes in the royalties. In the limiting case, if $U$ had no control at all such that $s$ were exogenously determined, and no pass-through were possible, different ways to split the total royalty would lead to different final allocations. More interestingly, consider the case where a single upstream producer sells to several downstream firms. In this case, royalty allocation neutrality would mean that the profits for all parties would be the same regardless of whether the patent holder charges a royalty upstream and (possibly) different royalties downstream or it only charges a royalty upstream and the upstream producer modifies the price of the intermediate product appropriately. However, it is often the case that the upstream producer

${ }^{28}$ Of course, even when this penalty exists there is a Nash Equilibrium where both firms declare that demand was low regardless of a true high realization. 
is serving several downstream producers for which the same input has a different added value. If, due to arbitrage or antitrust considerations, the upstream firm cannot charge different prices downstream, in contrast to what a patent holder might be able to accomplish using individual licensing negotiations, royalty allocation neutrality will fail. Furthermore, the upstream producer will tend to raise its intermediate price in a way that makes the doublemarginalization problem more severe, reducing as a result both profits and consumer welfare.

Example 5 (Arbitrage): Go back again to example 1 in a much simpler setup, where the upstream producer has all of the bargaining power, $\beta=1$, and the licensed technology brings production costs down to zero, $c=0$. Assume that the upstream firm serves two downstream producers. Each downstream producer sells to one consumer willing to buy one unit. The consumer in market 1 has a valuation $\theta_{l}$, while the consumer in market 2 has a lower valuation, $\theta_{2}<\theta_{1}$. It is immediate that the optimal contract in this case will call for the sum of the royalties to equal each valuation in turn, with intermediate prices s adjusting accordingly: $r_{U, 1}+r_{D, 1}=\theta_{1}, r_{U, 2}+r_{D, 2}=\theta_{2}, s_{1}=r_{U, 1}$ and $s_{2}=r_{U, 2} \cdot$

Assume now that the upstream producer, due for example to arbitrage, cannot price discriminate between the two downstream firms and is forced to sell in both markets at the same intermediate price, $s=s_{1}=s_{2}$. The optimal allocation can still be attained if all the royalty burden is shifted downstream so that $r_{U 1}=r_{U 2}=0$ and thus $s_{1}=s_{2}=0$. If this possibility is precluded, the upstream producer will need to choose between an intermediate value of $s$ that will reduce profits from market 1 , or if the difference between the two downstream valuations $\theta_{1}$ and $\theta_{2}$ is sufficiently high, the upstream producer can decide to sell only in market 1 . As a result, the patent holder will obtain lower profits and social welfare will surely decrease since market 2 will be left underserved or unattended altogether. 
As the previous example points out, in practice, this sort of friction is likely to arise when there is important heterogeneity in the uses (and the corresponding valuation) of the intermediate good produced by the upstream firm. This is likely to be the case for goods that have a general span of uses or markets for highly differentiated final products. The prediction of the model is that in this case the patent holder will tend to shift (at least some of) the royalty burden downstream. In this situation, different contracts can be written for firms with different needs.

This example is especially relevant for the Quanta case, as it appears that LGE had indeed issued blanket licenses to some, but not to all, downstream users. Intel therefore needed to distinguish between those licensees that were already covered by a blanket license from LGE and those that were not. ${ }^{29}$

\section{Double Dipping}

Critical to the concerns in the Quanta case was the notion that the patent holder was double dipping on royalty earnings. No formal definition of double dipping was given, however, and in the context of our model more than one definition is possible. In this section we discuss the two most natural interpretations and then show that under either one, the concerns about harmful effects are misplaced.

Under the first interpretation, the mere act of charging royalties in more than one stage of the production process is perceived as double dipping. Our analysis has already shown that

\footnotetext{
${ }^{29}$ For a discussion of the blanket licenses from LGE and their legal implications, see Richard A. Epstein, “What Is So Special About Intangible Property? The Case For Intelligent Carryovers” working paper, p. 35. See also, Richard A. Epstein, The Disintegration of Intellectual Property? A Classical Liberal Response to a Premature Obituary, 62 Stan. L. Rev. 455 (2010).
} 
this interpretation is in fact erroneous. Whenever the patent holder decides to move from charging a royalty in one of the stages to charging royalties in both stages it is in the holder's private interests to decrease the original royalty so that the already optimized aggregate royalty stays unchanged. As a result, this form of double dipping is harmless for social welfare, and indeed we have shown that in some circumstances multi-stage licensing might improve efficiency. ${ }^{30}$

A second intepretation of double dipping involves deception on the part of the patent holder to increase its aggregate royalty earnings. In this scenario, the patent holder would establish a royalty rate for one party, say the downstream producer, yet in the negotiation with the upstream producer the patent holder would pretend that a low royalty (or no royalty at all) has been agreed downstream. By doing so, the argument goes, the patent holder can extract a larger total payment from the parties. We devote the rest of this section to a discussion of this possibility.

Suppose that in the context of the previous model the patent holder engages in secret negotiations with both the upstream and the downstream producer, so that neither knows the terms agreed by the other. After the terms of the patent contracts have been reached the upstream and downstream producer negotiate the intermediate price $s$. Double dipping would mean that the patent holder would try to obtain a larger royalty from the upstream producer by claiming that little was being charged downstream, but in reality charge the downstream

\footnotetext{
${ }^{30}$ The key here is the ability to contract ex ante, before potential licensees have made any sunk investments. Ex post, if such irreversible investments have been made then multiple licenses may indeed “double dip”, but a better name for this behavior is patent hold up. In other words, “double dipping” is really only a special case of patent hold up and as such, is only a possible strategy ex post, when downstream firms have a good in the market before they seek a license on the IP that good relies on. First sale doctrine is not the best route to address such opportunistic licensing as the ability to hold up licensees hinges on the presence of irreversible investments and not on the ability to license multiple parties in the productin chain.
} 
producer a larger royalty as well, claiming that little was being charged upstream.

Is it in the interest of the patent holder to attempt such a deception? Suppose that the patent holder is successful. Increasing the upstream royalty $r_{U}$ would lead $U$ to increase $s$, which together with the downstream royalty $r_{D}$ would result in a downstream price higher than what has been obtained in the benchmark case where no private information existed. We therefore obtain that the aggregate royalty rate increases at the expense of a lower quantity of end goods sold (due to the increase in the input price which leads to an increase in the final price).

The patent holder will be better off only if the decrease in the quantity sold downstream is small compared to the increase in the royalty rate obtained. It can be shown, however, that this will never be the case since, as we have already discussed in the context of example 1, in the benchmark case the price of the final product was already higher than that which would have maximized the patent holder's profits due to the presence of double marginalization. In other words, the patent holder would rather see end prices fall so that larger quantities can be sold. If double dipping means a further increase in the final price, that strategy will surely lead to lower profits.

Of course, all of this analysis presumes that the patent holder can successfully deceive the upstream producer into believing that the downstream royalty is different than what it really is. In practice, the upstream producer is likely to anticipate this move. In Appendix B we study the resulting equilibrium in this case, and interestingly, we show that in the context of example 1, this counterargument leads to exactly the same royalty obtained in our benchmark case.

The bottom line on double dipping, then, is that as long as the upstream producer has any bargaining power at all (that is, as long as $\beta$ is not equal to zero) then the patent holder has no 
incentive to double dip. The presence of double marginalization that results from the upstream producer being able to earn a margin in its sale of the intermediate good means that the downstream price is higher than optimal, from both a social welfare viewpoint and from the perspective of the patent holder's private profits. Therefore, the patent holder will not benefit from increasing the aggregate royalty rates that it charges of the up and downstream producers.

\section{Conclusions}

Motivated by the arguments raised during the Quanta case, we have attempted to present a comprehensive analysis of the economics of patent licensing in a vertical relations environment. In an ideal setting, with no transaction costs or asymmetries of information, we find that the division of royalties among the different firms in the production process has no impact on social welfare. Different allocations will be more or less desirable inasmuch as the total royalty they represent is higher or lower than what is socially desirable. Charging just one versus charging multiple parties is not the pivotal element for social welfare.

But the idealized world presented in our benchmark case is likely to differ from the market reality. For instance, technology markets may be characterized by private information or wholesale pricing constraints. Even here, though, there is no justifcation for placing restrictions on the ability of patent holders to split fees among multiple production layers. In fact, in the face of transaction costs and frictions, a strict interpretation of first sale patent exhaustion is likely to generate welfare losses in the economically justified reward and efficiency dimensions of licensing discussed in the introduction. The reward from innovation decreases because the patent holder will likely obtain lower profits and efficiency will be reduced if the restrictions reduce the diffusion of innovations in downstream markets. 
We have identified several environments where the costs of a strict application of the first sale doctrine are likely to be relevant. The main one is related to informational asymmetries between the patent holder and the upstream and downstream producers. These asymmetries are likely to be particularly relevant in the case of technologies that have a range of applications, that can be embedded in a variety of products or that are used in combination with other products. Similarly, the reward that patent holders receive from their innovations is likely to be affected by licensing restrictions when the need to price disciminate in the downstream market is more important. In that case, a patent holder might do better in terms of screening different applications of the patented technology, in ways that upstream producers might be unable to replicate.

Our analysis thus shows that one of the key concerns raised in the Quanta case, that patent holders charging royalties at mutiple layers of the production process could be engaged in "double dipping”, is likely to be misplaced and will only apply under narrow circumstances. Our primary message is therefore that a balanced approach in the regulation of licensing of intellectual property is required. Expanding the strict application of the first sale doctrine would likely have detrimental effects for consumers and industry participants. A more flexible application of first sale's patent exhaustion, where its presence would be inferred only in the absence of license clauses to the contrary, is the preferrable approach from an economic perspective.

Our analysis also applies to other forms of IPR. For example, the issues addressed in this paper regarding the division of the total patent royalty are closely related to those that arise in the literature on the European doctrine known as droit de suite (DDS). The DDS rule - which began in France in the 1920s and over time was adopted in many European countries guarantees a royalty to the creator of a work of art over the price obtained in its future resale. 
Some authors, such as Ginsburg (2005), have raised a theoretical concern that DDS rules might reward authors in the phase of their careers when they are relatively less productive and might also distort the market by diverting artworks from DDS-friendly countries towards those where artists do not receive such a royalty. In contrast, applying our royalty neutrality analysis to DDS implies that the prices initially paid to an artist would adjust to reflect expected DDS payments made in the future. Empirical studies of DDS rules are consistent with our conclusions. In particular, the evidence presented in papers such as Graddy and Banterghansa (2009) show that the impact on future prices for artwork covered by DDS is negligible, as are any trading volume effects. If anything, the quantitative studies indicate that trading volume increases more in DDS-friendly countries.

Finally, observe that the model we study is not specific to the licensing of intellectual property. Our neutrality result does not lead to any advantage of charging different stages of production in the sale of a physical input (as opposed to intellectual property) and, naturally, this kind of contract will not arise if there is a cost of transacting with more than one of the parties. A firm that provides a platform, for example, can charge a price for its use by different firms or individuals that in turn, interact as sellers and buyers. Along these lines, an airport charges travelers for its use (e.g., taxes charged to passengers, typically added to the ticket price), whereas it also charges airlines for landing slots and restaurants and shops for the space they occupy on the premises. To the extent that these services are bought by travelers, the same sort of logic discussed above applies. ${ }^{31}$

\footnotetext{
${ }^{31}$ A possible difference is that, whereas in the case of intellectual property per-unit royalties arise naturally, this is not necessarily the case in these other examples. However, one can argue that the number of landing slots or the size of the store is related to the quantity sold. Similar issues arise in the literature on two-sided markets. See Rochet and Tirole (2002) and (2003) for more details.
} 


\section{Appendix A. General Royalty Allocation Neutrality Argument}

Proof of Proposition 1. Consider a market where firms $i=1, \ldots, I$ each produce one downstream product and $j=1, ., J$ firms each produce one upstream component. A patent holder owns intellectual property necessary for the production of the good. Assume that the marginal costs of production are $c_{U}^{j}$ and $c_{D}^{i}$ for the upstream and the downstream good producer, respectively. The patent holder charges a royalty $r_{U}^{j}$ and $r_{D}^{i}$ to upstream and downstream producers. Finally, upstream producer $j$ charges to final good producer $i$ a price $s_{i, j}$.

Denote as $\left\{r_{U}^{j^{*}}\right\}_{j=1}^{J},\left\{r_{D}^{i^{*}}\right\}_{i=1}^{I}$ a combination of royalties that maximizes profits for the patent holder. Denote as $q_{i, j}^{*}$ the quantity that downstream producer $i$ buys from upstream producer $j$ and $s_{i, j}^{*}$ its price. Profits for the patent holder can, therefore, be written as

$$
\Pi_{H}=\sum_{i=1}^{I} \sum_{j=1}^{J}\left(r_{U}^{j^{*}}+r_{D}^{i^{*}}\right) q_{i, j}^{*}
$$

where

$$
\sum_{j=1}^{J} q_{i, j}^{*}=D\left(p_{D}^{i *}\right) .
$$

Royalty allocation neutrality means that any other combination $\left\{r_{U}^{j}\right\}_{j=1}^{J},\left\{r_{D}^{i}\right\}_{i=1}^{I}$ with $r_{U}^{j}{ }^{\prime} \geq 0$ and $r_{D}^{i}{ }^{\prime} \geq 0$, and $r_{U}^{j^{\prime}}+r_{D}^{i^{\prime}}=r_{U}^{j^{*}}+r_{D}^{i^{*}}$ for all $i, j$ leads to the same profits. 
Towards a contradiction, assume that this is not the case and that the contract $\left\{r_{U}^{j}\right\}_{j=1}^{J}$, $\left\{r_{D}^{i}\right\}_{i=1}^{I}$ with upstream price $s_{i, j}^{\prime}$ and final sales sales $q_{i, j}^{\prime}$ produces strictly lower profits. Then, it must be the case that there exists at least a final good, say good $i$, for which total sales are lower under the alternative contract. Lower sales imply a higher final price for product $i$. Since profits are increasing in the cost of the product, there is at least one upstream producer, say firm $j$, for which

$$
r_{D}^{i^{\prime}}+s_{i, j}^{\prime}>r_{D}^{i^{*}}+s_{i, j}^{*}
$$

That is, the downstream producer is facing a higher total licensing cost of buying from the original upstream firm, and it might (or might not) switch to another provider.

Under the alternative contract, the total profits that firm $i$ and $j$ split can be written as

$$
\left(p_{D}^{i^{\prime}}-\left(c_{U}^{j}+c_{D}^{i}+r_{i}^{D^{\prime}}+r_{U}^{j^{\prime}}\right)\right) q_{i, j}^{\prime}
$$

where, by hypothesis, $q_{i, j}^{\prime}<q_{i, j}^{*}$. It is then, immediate, that the intermediate price $s_{i, j}^{\prime}$ does not maximize profits for the coalition between firm $i$ and $j$, since by choosing

$$
\hat{s} \equiv r_{D}^{i^{*}}-r_{D}^{i^{\prime}}+s_{i, j}^{*}
$$

the total profits to be divided would have increased. Given that we have assumed that the profits of each of the firms cannot decrease when the feasible set expands, the original intermediate price $s_{i, j}^{\prime}$ could not have been Pareto optimal at this stage, leading to a contradiction. 


\section{Appendix B. Optimal royalties under private information.}

Proposition 2. Consider a private information game where the patent holder chooses in the first stage $r_{U}$ and $r_{D}$, and where the upstream and downstream licensees do not observe the royalty imposed on the other firm. In the second stage the upstream producer chooses an intermediate price $s$ (that is $\beta=1$ ). The downstream firm faces a demand function $D(p)=1-p$, as in example 1 . Then, the aggregate royalty that maximizes the patent holder's profits is identical to the one obtained in the example 1.

Proof. Consider the case in example 1 with $\beta=1$. We start with the last stage of the game.

Given $r_{D}$ and $s$ the downstream producer chooses a price for the final $p^{*}=\frac{1+c+r_{D}+s}{2}$. The quantity produced is $q^{*}=1-p^{*}=\frac{1-c-r_{D}-s}{2}$.

In the second stage, after $r_{U}$ and $r_{D}$ have been chosen, the upstream producer has beliefs $\rho$ regarding the (unbserved) $\mathrm{r}_{\mathrm{D}}$. Given those beliefs, the chosen $s$ solves

$$
\max _{s}\left(s-r_{U}\right)\left(\frac{1-c-\rho-s}{2}\right)
$$

resulting in $s^{*}(\rho)=\frac{1-c-\rho+r_{U}}{2}$.

In the first stage, the patent holder maximizes

$$
\max _{r_{U}, r_{D}}\left(r_{U}+r_{D}\right) q^{*}=\max _{r_{U}, r_{D}}\left(r_{U}+r_{D}\right)\left(\frac{1-c-2 r_{D}+\rho-r_{U}}{4}\right)
$$

It is easy to observe that for a given $r_{U}+r_{D}$ profits are increasing if $r_{U}$ is increased and $r_{D}$ is decreased. Therefore, profits are maximized if is chosen at its minimum. That is, $r_{D}=0$. 
Since in equilibrium $\rho=r_{D}$ the profit function becomes

$$
\max _{r_{U}} r_{U}\left(\frac{1-c-r_{U}}{4}\right)
$$

which results in $r_{U}^{*}=\frac{1-c}{2}$ as stated. 


\section{References}

Beggs, A.W. 1992. The Licensing of Patents under Asymmetric Information. International Journal of Industrial Organization 10: 171- 191.

Bias, Bruno. 1983. Price Formation and Equilibrium Liquidity in Fragmented and Centralized Markets. The Journal of Finance 48: 157-85.

Bouquet, A., H. Cremer, M. Ivaldi, and M. Wolkowicz. 1998. Risk Sharing in Licensing. International Journal of Industrial Organization 16: 535- 554.

Brown-Hruska, Sharon and Paul A. Laux. 1999. Complementary Markets. Working Paper. Available at SSRN: http://ssrn.com/abstract=160208.

Choi, J.P. 2001. Technology Transfer with Moral Hazard. International Journal of Industrial Organization 19: 249- 266.

Coase, Ronald H. 1960. The Problem of Social Cost. Journal of Law \& Economics 3:144.

Epstein, Richard A. 2007. Some Reflections on Custom in the IP Universe. Virginia Law Review in Brief 93: 207-213.

Gallini, N.T., and B.D. Wright. 1990. Technology Transfer under Asymmetric Information. RAND Journal of Economics 21: 147- 160.

Gilbert, R. and C. Shapiro. 1990. Optimal Patent Length and Breadth. RAND Journal of Economics 21: 106-112.

Ginsburgh, Victor. 2005. The Economic Consequences of Droit de Suite in the European Union. Economic Analysis \& Policy 35:61-71.

Graddy, Kathryn and Chanont Banternghansa. 2009. The Impact of the

Droit de Suite in the UK: An Empirical Analysis. CEPR Discussion Paper

No. DP7136.

Green J. and S. Scotchmer. 1995. On the Division of Profit in Sequential Innovation. RAND Journal of Economics 26:20-33.

Jensen, R. and M. Thursby. 2001. Proofs and Prototypes for Sale: the Licensing of University Inventions. American Economic Review 91: 240- 259.

F. Scott Kieff. 2008. Quanta v. LG Electronics: Frustrating Patent Deals by Taking Contracting Options off the Table? CATO Supreme Court Review 2007-2008: 315-30.

Klemperer, P. 1990. How Broad Should the Scope of Patent Protection Be? RAND Journal of Economics 21:113-130.

Lafontaine, Francine. 1992. Agency Theory and Franchising: Some Empirical Results. RAND Journal of Economics 23: 263-83.

Macho-Stadler, I. and D. Pérez-Castrillo. 1996. An Introduction to the Economics of Information: Incentives and Contracts. Oxford, UK: Oxford University Press. 
Ordover, Janusz A., Garth Saloner and Steven C. Salop. 1990. Equilibrium Vertical Foreclosure, American Economic Review 80.

Rochet, J.C. and J. Tirole. 2002. Cooperation Among Competitors: Some Economics of Payment Card Associations. RAND Journal of Economics 33: 1-22.

Rochet, J.C. and J. Tirole. 2003. Platform Competition in Two-Sided Markes. Journal of the European Economic Association 1:990-1029.

Salop, S.C. and D. T. Scheffman. 1983. Raising Rivals” Costs. The American Economic Review 73: 267-271.

Schmidt, Klaus M. 2006. Licensing Complementary Patents and Vertical Integration. Discussion Paper N. 5987. Center for Economic Policy Research, London, UK.

Shapiro, Carl. Navigating the Patent Thicket: Cross Licenses, Patent Pools, and Standard Setting. 2001. Innovation Policy and The Economy 1, edited by Adam Jaffe, Josh Lerner, and Scott Stern. Cambridge: The MIT Press.

Spengler, J. 1950. Vertical Integration and Anti-trust Policy. Journal of Political Economy 58: 347-352. 


\section{CEMFI WORKING PAPERS}

0801 David Martinez-Miera and Rafael Repullo: "Does competition reduce the risk of bank failure?".

0802 Joan Llull: "The impact of immigration on productivity".

0803 Cristina López-Mayán: "Microeconometric analysis of residential water demand".

0804 Javier Mencía and Enrique Sentana: "Distributional tests in multivariate dynamic models with Normal and Student $t$ innovations".

0805 Javier Mencía and Enrique Sentana: "Multivariate location-scale mixtures of normals and mean-variance-skewness portfolio allocation".

0806 Dante Amengual and Enrique Sentana: "A comparison of mean-variance efficiency tests".

0807 Enrique Sentana: "The econometrics of mean-variance efficiency tests: A survey".

0808 Anne Layne-Farrar, Gerard Llobet and A. Jorge Padilla: "Are joint negotiations in standard setting "reasonably necessary"?".

0809 Rafael Repullo and Javier Suarez: "The procyclical effects of Basel II".

0810 Ildefonso Mendez: "Promoting permanent employment: Lessons from Spain".

0811 Ildefonso Mendez: "Intergenerational time transfers and internal migration: Accounting for low spatial mobility in Southern Europe".

0812 Francisco Maeso and Ildefonso Mendez: "The role of partnership status and expectations on the emancipation behaviour of Spanish graduates".

0813 Rubén Hernández-Murillo, Gerard Llobet and Roberto Fuentes: "Strategic online-banking adoption".

0901 Max Bruche and Javier Suarez: "The macroeconomics of money market freezes".

0902 Max Bruche: "Bankruptcy codes, liquidation timing, and debt valuation".

0903 Rafael Repullo, Jesús Saurina and Carlos Trucharte: "Mitigating the procyclicality of Basel II".

0904 Manuel Arellano and Stéphane Bonhomme: "Identifying distributional characteristics in random coefficients panel data models".

0905 Manuel Arellano, Lars Peter Hansen and Enrique Sentana: "Underidentification?".

0906 Stéphane Bonhomme and Ulrich Sauder: "Accounting for unobservables in comparing selective and comprehensive schooling".

0907 Roberto Serrano: "On Watson's non-forcing contracts and renegotiation".

0908 Roberto Serrano and Rajiv Vohra: "Multiplicity of mixed equilibria in mechanisms: a unified approach to exact and approximate implementation".

0909 Roland Pongou and Roberto Serrano: "A dynamic theory of fidelity networks with an application to the spread of HIV / AIDS".

0910 Josep Pijoan-Mas and Virginia Sánchez-Marcos: "Spain is different: Falling trends of inequality".

0911 Yusuke Kamishiro and Roberto Serrano: "Equilibrium blocking in large quasilinear economies".

0912 Gabriele Fiorentini and Enrique Sentana: "Dynamic specification tests for static factor models". 
0913 Javier Mencía and Enrique Sentana: "Valuation of VIX derivatives".

1001 Gerard Llobet and Javier Suarez: "Entrepreneurial innovation, patent protection and industry dynamics".

1002 Anne Layne-Farrar, Gerard Llobet and A. Jorge Padilla: "An economic take on patent licensing: Understanding the implications of the "first sale patent exhaustion" doctrine. 